\title{
Long-Term Follow-Up in a Girl with Cystic Fibrosis and Diabetes Since the First Year of Life
}

\author{
Valentina Fattorusso - Alida Casale · Valeria Raia • Enza Mozzillo • \\ Adriana Franzese
}

Received: May 7, 2017 / Published online: August 2, 2017

(c) The Author(s) 2017. This article is an open access publication

\begin{abstract}
Diabetes mellitus is the most common comorbidity in cystic fibrosis (CF). Recently, more attention has been paid to early glucose metabolism derangements (GMDs). The subject of this report is a female patient, affected by CF since 3 months of age. She presented with intermittent diabetes during early childhood. At the age of 10 years, oral glucose tolerance test (OGTT) was performed and showed glucose intolerance (IGT) status; glargine insulin therapy was started. At the age of 13 years, CF-related diabetes with fasting hyperglycemia occurred, so rapid insulin at meals was added. During the following year, clinical and nutritional status improved. Stable clinical conditions were observed in the following 3 years. This is the first case of very long-term follow-up concerning a CF patient with GMDs. Our case confirms the importance of paying attention to early GMDs in very young CF patients and seems to suggest that earlier therapy could ameliorate CF natural history.
\end{abstract}

Enhanced content To view enhanced content for this article go to http://www.medengine.com/Redeem/ F7F8F060003A0AFD.

V. Fattorusso $(\bowtie) \cdot$ A. Casale $\cdot$ V. Raia

E. Mozzillo · A. Franzese

Section of Pediatrics, Department of Translational

Medical Science (DISMET), University of Naples

Federico II, Naples, Italy

e-mail: vfattorusso1@gmail.com
Keywords: Cystic fibrosis; Cystic fibrosis-related diabetes; Diabetes in infancy; Glargine; Glucose metabolism derangements; Infant

\section{INTRODUCTION}

Diabetes mellitus is the most common comorbidity in cystic fibrosis (CF) people, occurring in $40-50 \%$ of adult patients and in a variable number of children and adolescents. Recently, more attention has been paid to other less severe glucose metabolism derangements (GMDs), since prediabetes may be related to increased morbidity, and early treatment may improve the clinical course in patients with CF [1]. According to the American Diabetes Association (ADA) classification, diabetes diagnosis is made in CF patients who present fasting blood glucose values greater than $7 \mathrm{mmol} / \mathrm{l}$ or glycemia greater than $11.1 \mathrm{mmol} / \mathrm{l}$ at time 120 of the oral glucose tolerance test (OGTT); the former condition is classified as CF-related diabetes-fasting hyperglycemia positive (CFRD-FH+) and negative (CFRD-FH-) respectively. By means of OGTT is also possible to differentiate glucose intolerance (IGT; glucose values 7.7$11.1 \mathrm{mmol} / \mathrm{l}$ at time 120); normal glucose tolerance (NGT; glucose values less than $5.5 \mathrm{mmol} / \mathrm{l}$ at time 0 and less than $7.7 \mathrm{mmol} / \mathrm{l}$ at time 120). CFRD prevalence increases with 
age and it is less than $2 \%$ among children younger than 10 years old, and for this reason official guidelines recommend to perform OGTT as screening test only after 10 years of age. On the other hand among the CF population aged less than 10 years, it is possible to detect early GMDs [1]. Beyond age, other risk factors are female gender, F508del homozygotes, severe pancreatic insufficiency, and corticosteroid use. Regarding clinical status, diabetes is associated with more severe pulmonary disease, more frequent pulmonary exacerbation or infections caused by resistant microorganisms, and more severe nutritional involvement. It has been demonstrated that early onset of hyperglycemia is related to a lower rate of survival and a higher rate of lung transplantation [1]. Furthermore, recently it has been questioned whether GMDs could influence health status of CF patients and whether insulin treatment, administered before overt diabetes, could be beneficial in reducing the number of pulmonary infections [1].

Here, we describe long-term follow-up in a CF patient with very early onset of diabetes.

\section{CASE REPORT}

The subject of this report is a female patient, affected by CF diagnosed at 3 months of age because of the presence of classic respiratory and gastrointestinal symptoms [2]. Genotype was F508del/F508del with classic CF phenotype. At the diagnosis, during oral corticosteroid treatment, the infant manifested high fasting plasma glucose (FPG) levels (33-35 mmol/L) and glycosuria, which required insulin therapy for 1 week at $0.6 \mathrm{U} / \mathrm{kg} / \mathrm{day}$. Insulin was stopped 2 days after steroid withdrawal. Laboratory investigation showed insulinopenia but excluded autoimmune causes of diabetes: human leukocyte antigen DR3/DR4 was negative; glutamic acid decarboxylase antibodies were negative. Family history for glucose intolerance or diabetes was negative. Hemoglobin A1c (HbA1c) levels were $31 \mathrm{mmol} / \mathrm{mol}$ (normal values $23-41 \mathrm{mmol} / \mathrm{mol}$ ). More details about this patient at onset have been described in a previous paper [2]. At 8 years of age, during a pulmonary exacerbation, which required steroid treatment, hyperglycemia recurred $(12.8 \mathrm{mmol} / \mathrm{L})$ but on immediately stopping steroid therapy no insulin was required. Two weeks later, OGTT was performed and showed "indeterminate glucose tolerance" status (named INDET [1], i.e., NGT patients with glucose value greater than $11.1 \mathrm{mmol} / \mathrm{l}$ at intermediate times during OGTT). One year later during the third pulmonary exacerbation treated with steroids, symptomatic diabetes occurred, which required 1 week insulin therapy at $0.8 \mathrm{U} / \mathrm{kg} /$ day. In the following 20 months five pulmonary exacerbation occurred which did not require steroid therapy and did not cause hyperglycemia. At the age of 10 years, OGTT was performed according current guidelines [1] away from pulmonary exacerbation and steroid therapy; it showed IGT status (glycemia peak at T90 of $16.88 \mathrm{mmol} / \mathrm{L}$ ); contemporary clinical conditions were worsening [increased number of pulmonary exacerbations, worsening of BMI $z$ score, and mean forced expiratory volume in $1 \mathrm{~s} \%$ (FEV1\%)]. Glargine insulin therapy $0.35 \mathrm{U} /$ $\mathrm{kg}$ /day once daily was started. During the following 2 years two pulmonary exacerbations occurred, FEV1\% was $97 \%$ of predicted value, and mean BMI $z$ score was -0.4 . When she was 13 years old, CFRD-FH+ occurred; HbA1c was $55 \mathrm{mmol} / \mathrm{mol}$. Insulin therapy was modified and rapid insulin at meals was added; total dose of administered insulin (rapid insulin + glargine) was $0.9 \mathrm{U} / \mathrm{kg} /$ day. During the following year, clinical and nutritional status improved: no pulmonary exacerbations were detected, FEV1\% remained stable, without the predicted annual decrease (3\%), BMI $Z$ score was -0.18 . Stable clinical conditions were observed in the following 3 years. When she was 16 years old, an increased rate of pulmonary exacerbations was observed, FEV1\% significantly decreased to $70.5 \%$, BMI $z$ score was -0.5 (Table 1), and $\mathrm{HbA1c}$ reached a value of $66.1 \mathrm{mmol} / \mathrm{mol}$.

\section{COMPLIANCE WITH ETHICS GUIDELINES}

Informed consent was obtained from the parents of the patient for being included in the case report. 
Table 1 Patient's key characteristics

\begin{tabular}{llllll}
\hline $\begin{array}{l}\text { Age } \\
\text { (year) }\end{array}$ & Diagnosis & Treatment & $\begin{array}{l}\text { Mean } \\
\text { FEV1\% }\end{array}$ & $\begin{array}{l}\text { Mean BMI } \\
\boldsymbol{z} \text { score }\end{array}$ & $\begin{array}{l}\text { Mean HbA1c\% } \\
(\mathbf{m m o l} / \mathbf{m o l})\end{array}$ \\
\hline $0-9$ & $\begin{array}{l}\text { CFRD, intermittent insulin } \\
\text { requirement }\end{array}$ & Rapid insulin (if occurred) & 110 & - & $5.4(35.5)$ \\
10 & IGT & Glargine 1/day $(0.35 \mathrm{U} / \mathrm{kg} /$ day $)$ & 97 & -0.40 & $6.2(44.3)$ \\
13 & CFRD-FH+ & Rapid insulin + glargine $(0.9 \mathrm{U} / \mathrm{kg} /$ day $)$ & 97 & -0.18 & $7.2(55.2)$ \\
16 & CFRD-FH+ & Rapid insulin + glargine $(0.9 \mathrm{U} / \mathrm{kg} /$ day $)$ & 70.5 & -1.52 & $8.2(66.1)$ \\
\hline
\end{tabular}

\section{DISCUSSION}

There are no outcomes data in the literature on CF patients who present with diabetes since infancy, and this is the first case report of very long-term follow-up concerning a CF patient with GMDs started in infancy.

In the literature only three cases of CFRD occurred in early childhood. The first was a female CF infant who presented with CFRD at 6 months [3]. The second was a female CF neonate who presented with transient diabetes which persisted during a 15-month follow-up and successively developed IGT [4]. The third was a male CF patient who developed CFRD at the age of 2 years, treated with insulin: this patient showed F508del/F508del, pancreatic insufficiency, and absence of autoimmunity; failure-to-thrive was present at diabetes diagnosis [5]. In the second and third cases, diabetes started without steroid therapy; on the contrary, our patient's diabetes was stimulated by steroid therapy, even if the inflammatory condition surely played a relevant role in starting diabetes by means of insulin resistance.

The long-term follow-up of our patient confirms that GMDs, when present in CF patients, appear to be never fully reversible and characterized by a progressive evolution which could worsen at the time of adolescence. Furthermore, our case confirms that the worsening of GMDs is parallel to the worsening of BMI $z$ score and FEV1\%. In addition, it is possible to think that earlier glargine administration could perhaps have reduced the worsening of nutritional status and pulmonary function (FEV1\%).

\section{CONCLUSION}

Our case confirms that GMDs in CF patients could appear even in infancy, that they are never fully reversible, and are progressive. For this reason, it is important to pay attention to early GMDs, even in patients aged less than 10 years, i.e., the age limit recommended by $\mathrm{CF}$ guidelines. In fact an earlier GMDs diagnosis could open the way to a more tailored therapy in order to ameliorate CF natural history.

\section{ACKNOWLEDGEMENTS}

No funding or sponsorship was received for this study or publication of this article. The article processing charges were funded by the authors. All named authors meet the International Committee of Medical Journal Editors (ICMJE) criteria for authorship for this manuscript, take responsibility for the integrity of the work as a whole, and have given final approval for the version to be published.

Compliance with Ethics Guidelines. Informed consent was obtained from the parents of the patient included in the case report.

Disclosures. Valentina Fattorusso, Alida Casale, Valeria Raia, Enza Mozzillo, and Adriana Franzese have nothing to disclose.

Data Availability. The datasets generated and/or analyzed during the current study are available from the corresponding author on reasonable request. 
Open Access. This article is distributed under the terms of the Creative Commons Attribution-NonCommercial 4.0 International License (http://creativecommons.org/licenses/ by-nc/4.0/), which permits any noncommercial use, distribution, and reproduction in any medium, provided you give appropriate credit to the original author(s) and the source, provide a link to the Creative Commons license, and indicate if changes were made.

\section{REFERENCES}

1. Franzese A, Mozzillo E, Fattorusso V, Raia V, Valerio G. Screening of glucose metabolism derangements in pediatric cystic fibrosis patients: how, when, why. Acta Diabetol. 2015;52(4):633-812.

2. Lombardi F, Raia V, Spagnuolo MI, Nugnes R, Valerio G, Ciccarelli G, Franzese A. Diabetes in an infant with cystic fibrosis. Pediatr Diabetes. 2004;5(4):199-201.

3. Milner AD. Blood glucose and serum insulin levels in children with cystic fibrosis. Arch Dis Child. 1969;44:351-5.

4. Siahanidou T, Mandyla H, Doudounakis S, Anagnostakis D. Hyperglycemia and insulinopenia in a neonate with cystic fibrosis. Acta Paediatr. 2005;94(12):1837-40.

5. Casas L, Berry DR, Logan K, Copeland KC, Royall JA. Cystic fibrosis related diabetes in an extremely young patient. J Cyst Fibros. 2007;6(3):247-9. 